\title{
Primary unilateral and bilateral cleft lip and nose in an older population
}

\author{
Kimit Rai MD FRCSC
}

\begin{abstract}
K Rai. Primary unilateral and bilateral cleft lip and nose in an older population. Can J Plast Surg 2005;13(2):71-74.

A one-stage procedure to reconstruct complete and incomplete unilateral/bilateral cleft lip and nose deformities is presented. Emphasis was made on closure of the lip muscles, correction of the nostril floor, correction of the alveolar cleft as well as reconstruction of the nose through an intranasal approach, with a supported suture technique for nasal correction. No dental or orthodontic treatment was available or performed in this older population. Emphasis was on primary closure of the muscles, using the rotation advancement principle. The repair that was performed was near anatomical, reconstructing the labial sulcus, the nostril floor, the alveolar cleft and the nasal deformity all in one stage. There was a high level of satisfaction both from the patient's and surgeon's point of view.
\end{abstract}

Key Words: Intranasal suture technique for alar dome symmetry; Muscle repair anatomical; Rotation advancement

$\mathrm{T}$ he most common developmental anomalies of the face are the cleft lip and palate, and this is the fourth most common birth defect in North America. The incidence of clefts in the developing world is approximately one in 500 live births; in North America, it is approximately one in 800 live births.

Treatment of cleft lip focuses on improving appearance and correcting functional problems. The cleft palate is repaired to ensure function in terms of normal speech development; specifically, proper pronunciation and articulation. Cleft palate can also include dental and middle ear problems. Because of the abnormal orientation of the palatal musculature around the pharyngeal opening of the eustachian tube, middle ear infections are very common. Almost all of these children require myringotomy tubes as prophylaxis against longterm hearing loss. For these reasons, cleft deformities in North American-born children are typically repaired in infancy. Unfortunately, in many developing countries, where adequate medical care may not be accessible or affordable, it is common for patients to present as adolescents or adults with unrepaired clefts. It has been estimated that up to $25 \%$ of patients requesting cleft corrective surgery in these countries are adults (1). These patients seek aesthetic correction of their lip and nose deformities so that they may be better accepted and integrated into society.

Despite this high incidence of adult cleft patients, the literature addressing this topic is scarce. Furthermore, there is currently no protocol for the management of cleft deformities in adult patients (1).

\author{
Fissure labiale et nasale unilatérale et \\ bilatérale primaire chez la personne âgée
}

Une intervention en une étape visant la reconstruction complète et partielle des fissures labiales et nasales unilatérales/bilatérales est présentée ici. On insiste sur la fermeture des muscles labiaux, sur la correction du plancher nasal, la correction de la fissure alvéolaire et la reconstruction du nez par le biais d'une approche intranasale avec technique de suture soutenue pour la correction nasale. Aucun traitement dentaire ou orthodontique n'était disponible ou n'a été effectué chez cette population âgée. On met l'accent sur la fermeture primaire des muscles basée sur un principe d'avancement et de rotation. La réparation qui a été effectuée était quasi-anatomique, a permis la reconstruction du sulcus labial, du plancher nasal, la réparation de la fissure alvéolaire et de la difformité nasale en une étape. On a noté un fort degré de satisfaction, tant de la part des patients que du chirurgien.

New Westminster, British Columbia

Correpondence: Dr Kimit Rai, \#405 301 East Columbia Street, New Westminster, British Columbia V3L 3W5. Telephone 604-522-2925,

fax604-522-1422,e-mail kimit_rai@bc.sympatico.ca

\begin{abstract}
Anatomy of the cleft palate
The lip and palate structures can be divided anatomically into the primary palate (prepalatal) and the secondary palate (palatal), which have different embryological developments and, thus, are divided by the incisive foramen (Figure 1A, 1B and $1 \mathrm{C}$ ). The primary palate forms from three mesenchymal islands: one central and two lateral. Incomplete migration and fusion of these islands leads to cleft deformities that involve the lip, alveolus, nose and nasal cartilages. Cleft lip may be unilateral or bilateral, complete or incomplete. The secondary palate develops later, and at seven weeks is composed of two palatal shelves that are vertically oriented along the sides of the tongue (Figure 1D). As the neck of the fetus straightens, the palatal shelves rotate upward to become horizontally oriented by week 12 of the pregnancy. Cleft palate can involve the hard palate, soft palate and uvula. Various combinations of clefts of the primary and secondary palate can be seen in Figure 2 .
\end{abstract}

\section{PATIENTS AND METHODS}

Presented here are experiences with patients that were seen on a two-week mission with Operation Rainbow Canada. Operation Rainbow Canada is a charitable organization that performs free surgery on children and adults in developing countries. The mission in Chandigarh, India included a team of Canadian plastic surgeons, a pediatrician, anesthesiologists, operating and recovery room nurses, and a support group. Using a one-stage procedure, complete repair of both the lip and nose deformities was achieved, with definitive flap repair of the alveolar cleft deformity. The total 

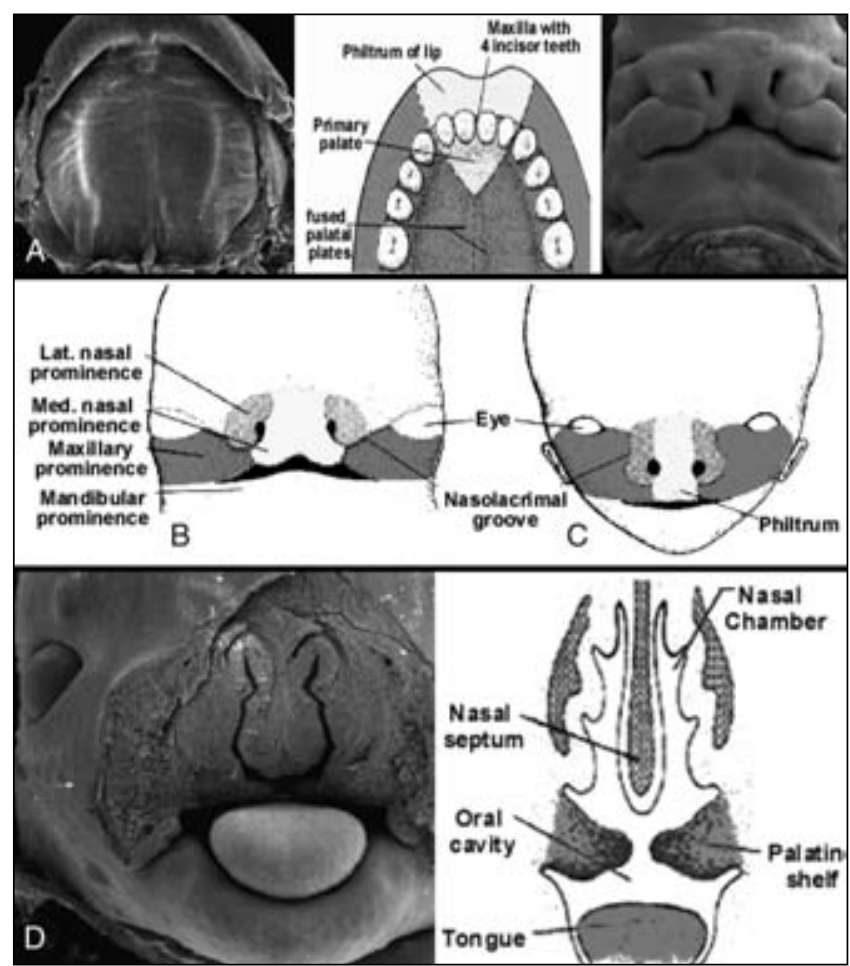

Figure 1) A Anatomy and embryology; B and C Embryology; D Palatal shelves

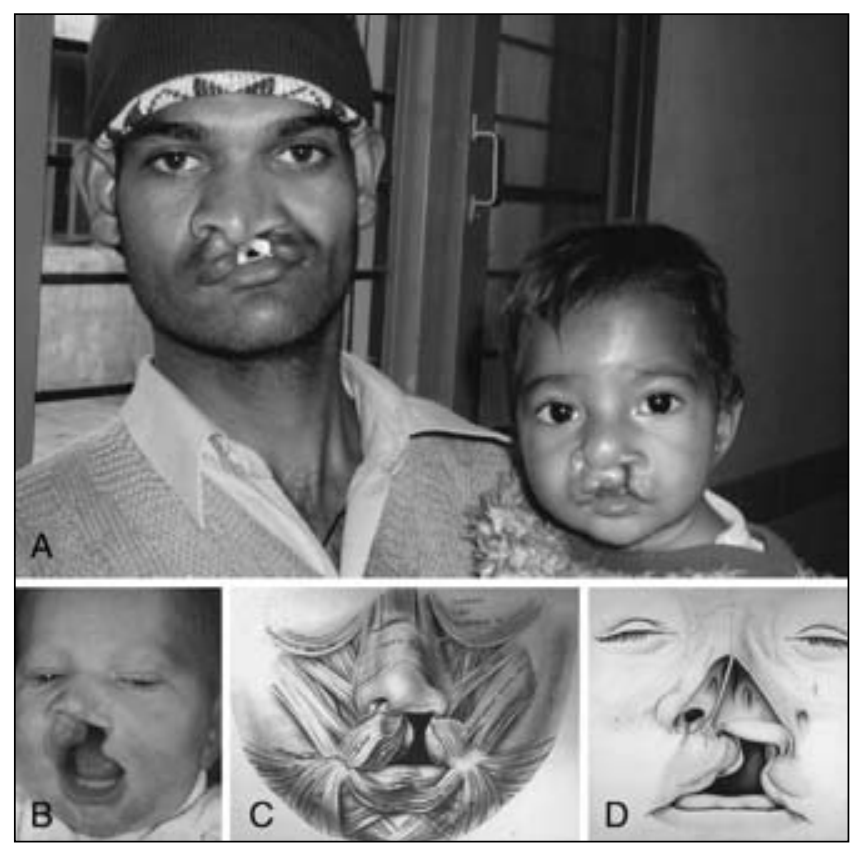

Figure 2) A Father - unilateral cleft lip and nose deformity; Child bilateral cleft lip and palate deformity; B Cleft lip; C Muscle elevation; $\mathrm{D}$ Lip and nose deformity

number of patients who registered for this program was 203, of which 49 were excluded due to additional comorbidities such as gastrointestinal problems, tuberculosis or meningitis. Ninety-one procedures were performed to correct cleft lip and nose and palatal deformities. Unilateral lip and nose deformities were corrected at
TABLE 1

Distribution of patients 10 years of age and older who were surgically treated

\begin{tabular}{lc}
\hline Presentation & \\
Unilateral cleft lip, nose and alveolar deformities & 20 male/8 female \\
Bilateral cleft lip, nose and alveolar deformities & 5 female
\end{tabular}

Procedure

Rotation advancement with nostril correction using

an intranasal approach with suture technique

Operated on for bilateral lip deformities with rotation advancement of muscle flap reconstruction as one primary procedure in a single-stage

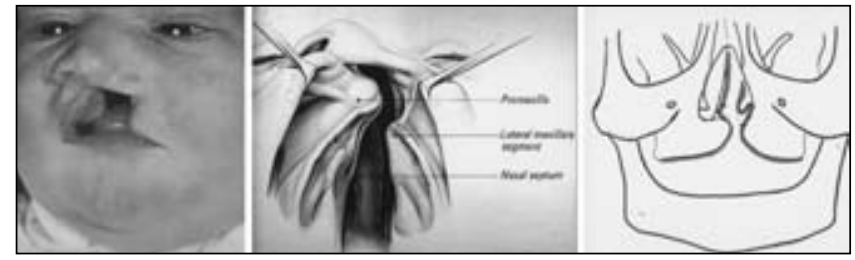

Figure 3) Periosteal flap dissection for alveolar cleft repair

the same time. Bilateral cleft lips were repaired using rotational advancement primary repair in a one-stage procedure. Any alveolus deformities were also repaired concurrently, so that the nostril floor was reconstructed at the same time as the primary lip repair.

There was a total of 33 patients from age 10 to 37 years (Table 1 ). All of the patients presented with very severe maxillary hypoplastic deformities, with mismatched maxillary arches and poor oral dentition. In some patients, the alveolar teeth were so displaced that they projected over 90 degrees in an overbite. Because this directly affected the surgical repair, these teeth were extracted. Asymmetrical arches were noted, but left uncorrected because orthodontic treatment was unavailable. The surgical repair for unilateral cleft lip involved modified rotation advancement. The alveolar deformities were managed with a nostril floor reconstruction using the technique described below. Both the lip and nose deformities were corrected at the same time in a one-stage procedure. This required repositioning the alar cartilages to their anatomical position when adequate lip exposure had been achieved at the time of surgery. The alar cartilages were then supported by a suture technique that did not entail any intranasal incisions (2). Using the rotation advancement principle, sufficient lip length was achieved. Muscle dissection played a major role in the reconstruction process and all three tissue layers were closed: mucosa, muscle and skin. In bilateral cases, the same principle of a one-stage repair with rotation advancement was used. The alveolar deformities were closed in all cases. This required mobilization of the periosteal lining of the alveolus and the periosteum of the intranasal alar base (Figure 3). The septal mucosal flap was separated to achieve reconstruction of the nostril floor. In the bilateral cases, nasal correction was performed by suturing the medial crura to narrow the broad nasal tip.

Surgical technique

Unilateral cleft lip surgical repair is a technique in which not only rotation advancement reconstruction of the lip musculature is achieved, but also the nose is corrected by an intranasal incision at the columella base (3). This releases the cartilages and secures the 


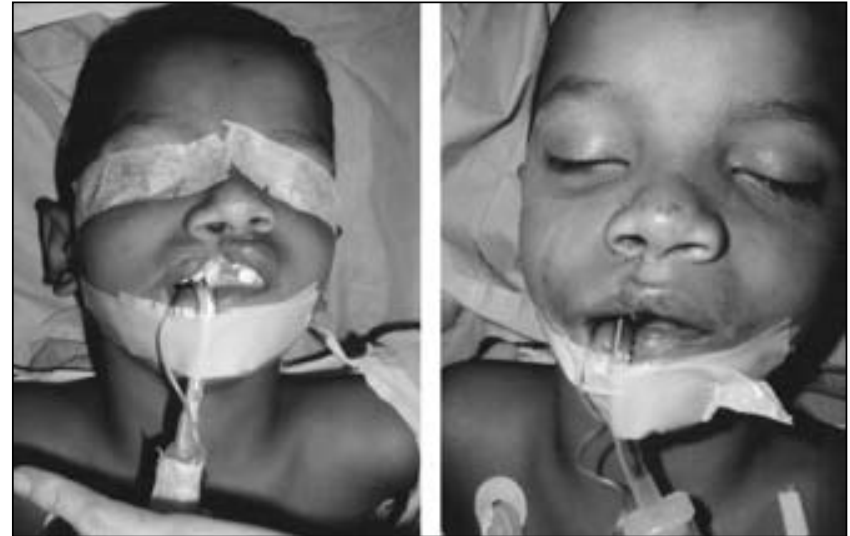

Figure 4) Preoperative lip and nose deformity (left); postoperative correction (right)
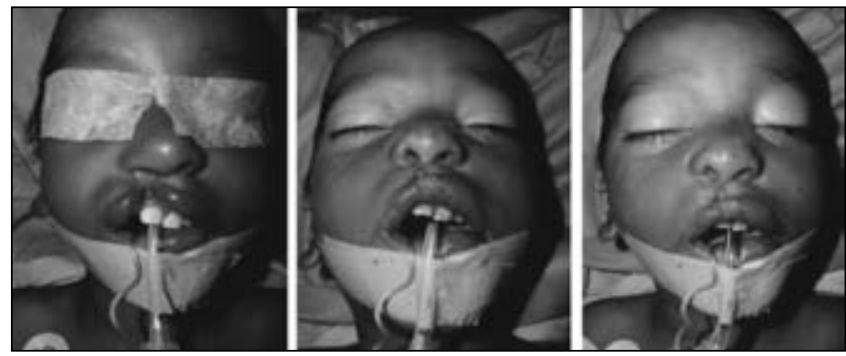

Figure 5) Unilateral right-sided complete cleft lip (left); Lip and nose correction postoperatively (centre and right)

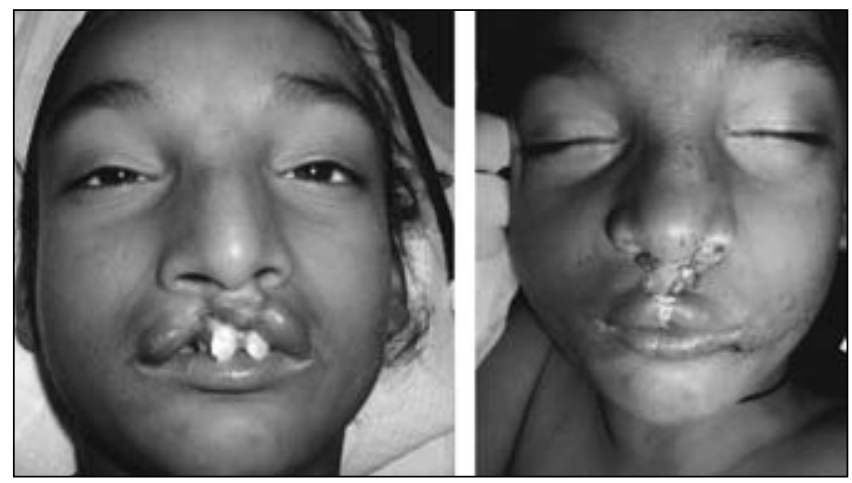

Figure 6) Bilateral incomplete cleft lip before (left) and after (right) surgery
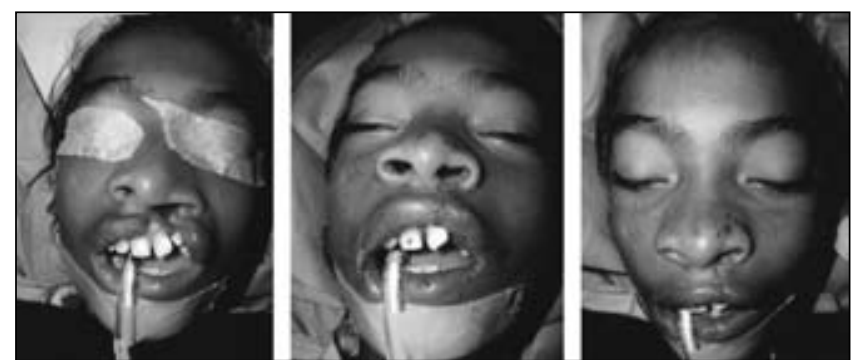

Figure 7) Preoperative lip and nose deformity (left); postoperative correction (centre and right)

slumped, deformed cartilage on the cleft side so it can be supported by suture technique on the noncleft side. No intranasal incisions are made except to support the alar dome. This allows reconstruction of the alar dome and base with sutures, as has been described by Dr Louise Caouette-Laberge (Coomb's suture) (4). Patients

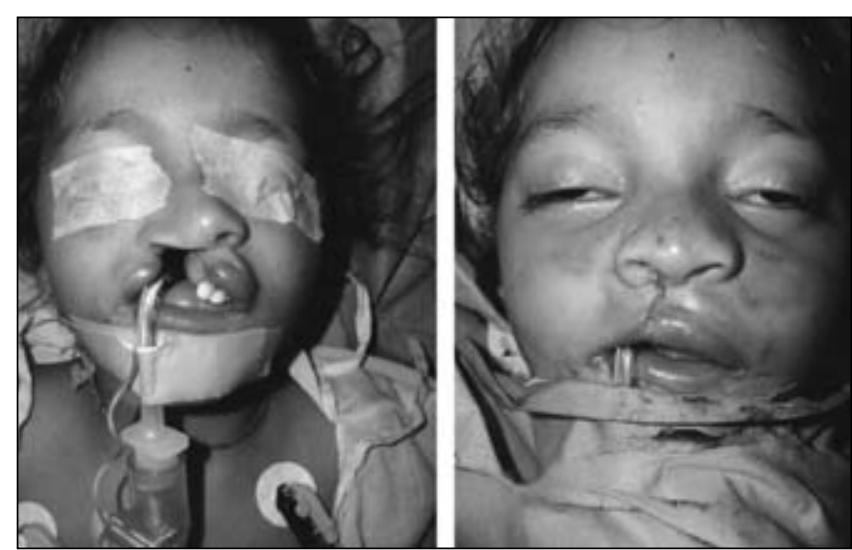

Figure 8) Unilateral cleft lip, nose, alveolus and palate deformity before (left) and after (right) surgical correction

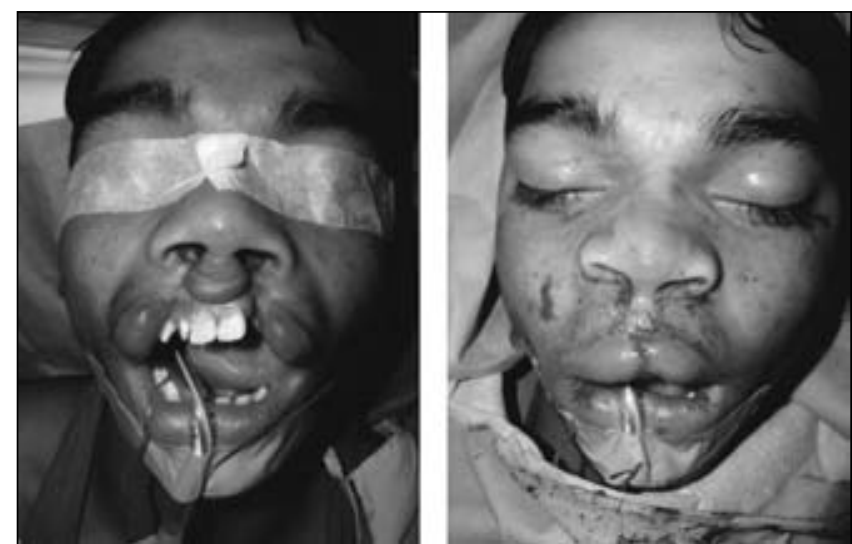

Figure 9) Bilateral complete cleft lip, nose and palate deformity (left); Bilateral lip, nose and alveolus repair (right)
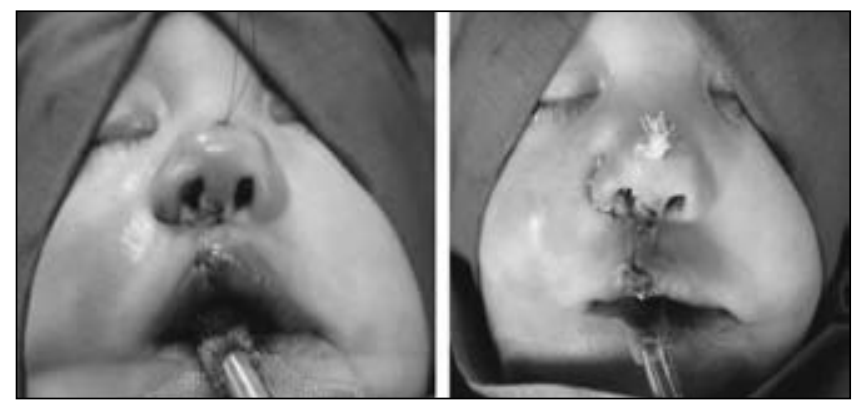

Figure 10) Primary nasal correction

with alveolar cleft deformities had the deformity closed at the same time as the cleft lip and nose and an alar base periosteal flap to reconstruct the nostril floor. This avoids an alveolus fistula when the lip has been completely repaired. In the bilateral cases, both lip deformities are repaired in one stage with concurrent reconstruction of the nostril floor using the above-mentioned flap (Figures 4 to 10 ).

\section{RESULTS}

Overall, the results were excellent with very high satisfaction levels among both patients and families. The last evaluations were conducted two weeks postoperatively. There was no area of breakdown in either the unilateral or bilateral cleft lip 
repairs, or in the corrected nose deformities. All of these patients had an intradermal repair using absorbable sutures (histoacryl) and skin reapproximation using steristrips. One year follow-up data and pictures of the repairs from the local plastic surgeons are highly anticipated.

\section{DISCUSSION}

There is an enthusiastic tendency to repair cleft lip, nose and alveolar deformities in one stage with the aim of achieving a near normal facial appearance.

In older patients, very little has been published regarding primary repair of cleft lip and nose deformities.

In our population of patients, extreme distortions of the lip and nose were seen in the unrepaired patients. Septal deviations, hypoplastic maxillae and alveolar defects were predominant. Severe dental deformities were also present with poor oral hygiene. Surgical repairs were performed using Millard Rotation Advancement skin incisions, keeping the scars to a minimum with meticulous repair of the orbicularis oris muscle in layers and, thus, maintaining oral continuity. At the same time, reconstruction of the nostril floor was performed in the alveolar cleft cases. Correction of the nostril deformity on the cleft side was performed by suturing the alar domes to anatomical position. Dental deformities and hypoplastic maxillae were not corrected at this time.

Follow-up evaluations of our population of older patients were performed four to six months postoperatively by
Dr Maninder Kaur, Administrator, and local plastic surgeon Dr Chanjiv Singh; discussions were had with Dr Kaur and Dr Singh by telephone from India. All of the patients were happy and satisfied with our surgeries.

\section{CONCLUSIONS}

Cleft lip, nose and alveolar deformities in the mature population can be repaired in one stage using the technique presented. This allows for satisfactory aesthetic results, both from the patient's and surgeon's view. The ability to correct extensive deformities in one step is also beneficial to surgeons performing these corrective procedures in other countries where they may have limited time.

ACKNOWLEDGEMENTS: Thank you to Dr Louise CaouetteLaberge; Dr Donald Fitzpatrick; and Kiran Manhas, University of British Columbia medical student, for their assistance in preparing this paper.

\section{REFERENCES}

1. Ahuja RB. Primary definitive nasal correction in patients presenting for late unilateral cleft lip repair. Plast Reconstr Surg 2002;110:17-24.

2. Wong GB, Burvin R, Mulliken JB. Resorbable internal splint: An adjunct to primary correction of unilateral cleft lip-nasal deformity. Plast Reconstr Surg 2002;110:385-91.

3. Seagle MB, Furton LT Jr. Muscle reconstruction in cleft lip repair. Plast Reconst Surg 2004;113:1537-47.

4. Wolfe SA. A pastiche for the cleft lip nose. Plast Reconstr Surg 2004:114:1-9. 